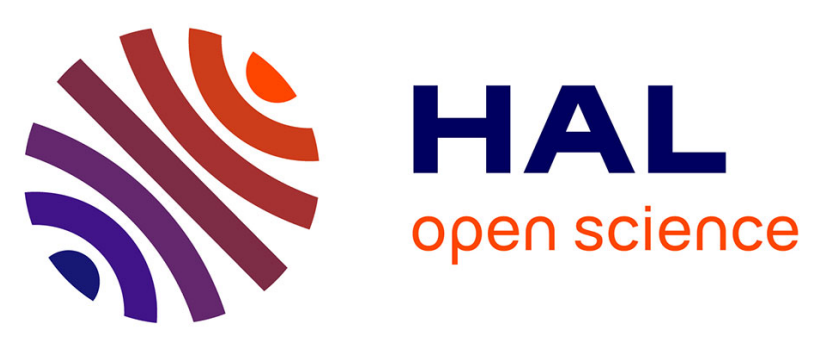

\title{
Plasma DBD activated ceria-zirconia-promoted Ni-catalysts for plasma catalytic CO2 hydrogenation at low temperature
}

Rafik Benrabbah, Charles Cavaniol, Hongrui Liu, Stéphanie Ognier, Simeon Cavadias, Maria Elena Gálvez, Patrick da Costa

\section{To cite this version:}

Rafik Benrabbah, Charles Cavaniol, Hongrui Liu, Stéphanie Ognier, Simeon Cavadias, et al.. Plasma DBD activated ceria-zirconia-promoted Ni-catalysts for plasma catalytic CO2 hydrogenation at low temperature. Catalysis Communications, 2016, 89, pp.73 - 76. 10.1016/j.catcom.2016.10.028 . hal01400667

\section{HAL Id: hal-01400667 https: / hal.sorbonne-universite.fr/hal-01400667}

Submitted on 22 Nov 2016

HAL is a multi-disciplinary open access archive for the deposit and dissemination of scientific research documents, whether they are published or not. The documents may come from teaching and research institutions in France or abroad, or from public or private research centers.
L'archive ouverte pluridisciplinaire HAL, est destinée au dépôt et à la diffusion de documents scientifiques de niveau recherche, publiés ou non, émanant des établissements d'enseignement et de recherche français ou étrangers, des laboratoires publics ou privés. 


\title{
Plasma DBD activated ceria-zirconia-promoted Ni-catalysts for plasma catalytic $\mathrm{CO}_{2}$ hydrogenation at low temperature
}

Rafik Benrabbah ${ }^{\mathrm{a}}$, Charles Cavaniol ${ }^{\mathrm{b}}$, Hongrui Liu ${ }^{\mathrm{a}}$, Stéphanie Ognier $^{\mathrm{b}}$, Simeon Cavadias ${ }^{\mathrm{b}}$, Maria Elena Gálvez ${ }^{\mathrm{a}}$, Patrick Da Costa ${ }^{\mathrm{a}}$ *

${ }^{a}$ Sorbonne Universités, UPMC, Univ. Paris 6, CNRS, UMR 7190, Institut Jean Le Rond d'Alembert, 2 place de la gare de ceinture, 78210 Saint-Cyr-L'Ecole, France

${ }^{\mathrm{b}}$ Institut de Recherche de Chimie Paris, IRCP, CNRS-Chimie Paristech-PSL, 11 rue Pierre et Marie Curie - 75005 Paris 11 rue Pierre et Marie Curie, 75005 Paris, France

*Corresponding author. Tel: +33-1-30854865; fax: + 33-1-30854899,

patrick.da_costa@upmc.fr

\begin{abstract}
The activity of Ceria-Zirconia supported Ni catalysts was measured in a hybrid cold dielectric barrier discharge (DBD) plasma-catalytic process for the hydrogenation of carbon dioxide into methane at low temperatures. Hydrogen DBD plasma treatment at room temperature was chosen as an alternative activation to conventional reduction performed at high temperature. The plasma-catalytic tests performed in the presence of the plasma-treated catalyst clearly show that the hydrogen plasma treatment can replace the high-temperature reduction in hydrogen.
\end{abstract}

Keywords: $\mathrm{CO}_{2}$-methanation, catalytic plasma activation, nickel catalysts 


\section{Introduction}

With the increase of energy consumption leading to global warming, $\mathrm{CO}_{2}$ emissions will be controlled. Thus, $\mathrm{CO}_{2}$ valorisation processes need be developed in order to stabilize the future $\mathrm{CO}_{2}$ emissions. Among them, $\mathrm{CO}_{2}$ methanation, i.e. Sabatier reaction, is considered as one of the most effective technologies for $\mathrm{CO}_{2}$ valorisation, offering moreover a feasible route for renewable $\mathrm{H}_{2}$ storage and utilisation [1,2] and syn-methane production. $\mathrm{CO}_{2}$ methanation is catalytic reaction in which $\mathrm{Ni}$ and $\mathrm{Ni}-\mathrm{Ru}$ supported on diverse porous materials [1,3-6]. However, relatively high temperatures are needed to reach acceptable conversions. Recently, it was shown that a plasma DBD catalytic process can lead to high conversions of $\mathrm{CO}_{2}$ and high $\mathrm{CH}_{4}$ selectivity at temperatures lower than $200^{\circ} \mathrm{C}[3,7,8,9]$. Plasma technologies can also be used for catalytic synthesis [10-15]. In general, there are three main trends in catalyst preparation using plasma technologies: plasma chemical synthesis of ultrafine particle catalysts [11,12], plasma assisted deposition of catalytically active compounds on various supports [13-15] and plasma enhanced preparation or plasma modification of catalysts $[12,16,17]$. A recent work evidenced that radio frequency or microwave plasma treated catalysts led to higher catalytic efficiency in $\mathrm{NO}_{\mathrm{x}}$ abatement for hydrocarbon SCR (Selective Catalytic Reduction) in comparison to classical calcined catalysts $[15,18]$.

A non-thermal hydrogen plasma reduction pre-treatment is proposed herein as an alternative to conventional high-temperature reduction. The activity and selectivity of both plasma-treated and conventionally reduced $15 \% \mathrm{Ni} / \mathrm{CeZrO}_{2}$ catalysts in the coupled DBDcatalytic $\mathrm{CO}_{2}$ methanation is compared. 


\section{Experimental}

\subsection{Catalysts synthesis and activation}

Catalysts were prepared through conventional wet impregnation of a commercial ceria-zirconia mixed oxide $\left(\mathrm{Ce}_{0.58} \mathrm{Zr}_{0.42} \mathrm{O}_{2}\right.$, Rhodia-Solvay). The Ni loading was 15 wt.\% $\left(\mathrm{Ni}\left(\mathrm{NO}_{3}\right)_{2} \cdot 6 \mathrm{H}_{2} \mathrm{O}\right.$ used as precursor). After impregnation, the Ni-impregnated ceria-zirconia were dried overnight at $100^{\circ} \mathrm{C}$ and subsequently calcined at $550^{\circ} \mathrm{C}$ for $4 \mathrm{~h}$. The calcined materials were then activated under different conditions. The catalyst Ni15RED470 was reduced under $\mathrm{H}_{2}$ through temperature-programmed reduction $\left(5^{\circ} \mathrm{C} / \mathrm{min}\right)$ followed by isothermal reduction at $470^{\circ} \mathrm{C}$ for $2 \mathrm{~h}$, as described elsewhere [8,9]. Three other catalysts were activated in a dielectric barrier discharge (DBD) plasma reactor operating at atmospheric pressure. It consisted of two coaxial tubes (quartz/alumina tubes), having internal diameters of 8 and $2.7 \mathrm{~mm}$ (2.15 $\mathrm{mm}$ gap), and $100 \mathrm{~mm}$ of effective length. A high-voltage alternating current in the range of $15 \mathrm{kV}(42.5 \mathrm{kHz})$ was applied in order to create DBD plasma, corresponding to a power at $8 \pm 0.5 \mathrm{~W}$ (adiabatic bed temperature of $100^{\circ} \mathrm{C}$, due to the exothermicity of the reduction process $) .300 \mathrm{mg}\left(0.6 \mathrm{~cm}^{3}\right)$ of catalyst were placed at the annular space of the discharge zone in DBD reactor. Pure $\mathrm{H}_{2}$ was fed at $160 \mathrm{~mL} / \mathrm{min}$ $\left(\mathrm{GHSV}=16,000 \mathrm{~h}^{-1}\right)$, for 20,40 and 60 minutes. The resulting catalysts were named Ni15PDBD20, Ni15PDBD40 and Ni15PDBD60.

\subsection{Physico-chemical characterization}

The specific surface area (BET) was calculated from $\mathrm{N}_{2}$ adsorption isotherms acquired at $-196^{\circ} \mathrm{C}$ (degas: $150^{\circ} \mathrm{C}, 4 \mathrm{~h}$, BELSORP-MINI-II-BEL JAPAN). X-ray diffraction (XRD) patterns were recorded in a diffractometer (PANalytical,CuKa source). Temperatureprogrammed reduction (TPR) and $\mathrm{CO}_{2}$-TPD were performed using a BEL-Japan-BELCATM. TPR were carried out using under $25 \mathrm{~mL} / \mathrm{min}$ of a $5 \%$ vol. $\mathrm{H}_{2} / \mathrm{Ar}$ mixture $\left(10^{\circ} \mathrm{C} / \mathrm{min}, 25\right.$ - 
$950^{\circ} \mathrm{C}$ ) with $50 \mathrm{mg}$ of activated catalysts. $\mathrm{CO}_{2}-\mathrm{TPD}$ experiments were carried out on activated catalysts with an adsorption at $80^{\circ} \mathrm{C}$ with $10 \%$ vol. $\mathrm{CO}_{2} / \mathrm{He}$ for 1 h followed by desorption under $\mathrm{He}$ for 20 minutes at $80^{\circ} \mathrm{C}$, then from 80 to $900^{\circ} \mathrm{C}$ with a heating rate of $10^{\circ} \mathrm{C} / \mathrm{min}$.

\subsection{Hybrid Plasma-Catalytic Methanation}

The activity in $\mathrm{CO}_{2}$-methanation was evaluated under adiabatic conditions, at temperatures from $120^{\circ} \mathrm{C}(3 \mathrm{~W})$ to $170^{\circ} \mathrm{C}(16 \mathrm{~W})$, in the same dielectric barrier discharge (DBD) plasma reactor used for activation/reduction. In all the cases a gas mixture of pure hydrogen and carbon dioxide with a $\mathrm{H}_{2} / \mathrm{CO}_{2}=4: 1$, at a flow rate of $200 \mathrm{~mL} / \mathrm{min}$ $\left(\mathrm{GHSV}=20,000 \mathrm{~h}^{-1}\right)$, was fed to the reactor.

In the hybrid plasma-catalytic methanation experiments, an alternative current (AC) high voltage (operating frequency: $40-42.8 \mathrm{kHz}$ ) of $13-18 \mathrm{kV}$ was applied to the discharging electrode to create non-thermal plasma. It varied in the range of $73-378 \mu \mathrm{J} /$ cycle, corresponding to a power between 3 and $16 \mathrm{~W}$, with electricity consumption lower than 50 $\mathrm{kJ} / \mathrm{mole}_{\mathrm{CH} 4}$ in the best case (40 min, (4W)). The voltage applied to the plasma-catalytic reactor was measured with a digital oscilloscope (PicoScope 5243A) using a probe (ELDITEST GE 3830).

The concentration of $\mathrm{CO}_{2}, \mathrm{CO}, \mathrm{H}_{2}$ and $\mathrm{CH}_{4}$ in the inlet and outlet gas streams were measured with the aid of a Varian 490 microGC equipped with a $5 \mathrm{~m} P B Q / 10 m$ MS and 10m PPU columns, and TCD detectors. The $\mathrm{CO}_{2}$ conversion $\left(X_{\mathrm{CO}_{2}}, \%\right)$, and $\mathrm{CH}_{4}$ selectivity $\left(\mathrm{S}_{\mathrm{CH}_{4}}, \%\right)$, and $\mathrm{CH}_{4}$ yield $\left(Y_{\mathrm{CH}_{4}}, \%\right)$, were calculated as follows:

$$
X_{\mathrm{CO}_{2}}=\left(n_{\mathrm{CO}_{2}}^{\text {in }}-n_{\mathrm{CO}_{2}}^{\text {out }}\right) /_{n_{\mathrm{CO}_{2}}^{\text {in }}} \times 100
$$


$S_{\mathrm{CH}_{4}}={ }^{n_{\mathrm{CH}}}{ }^{\mathrm{out}} /\left(n_{\mathrm{CH}_{4}}^{\text {out }}+n_{\mathrm{CO}}^{\text {out }}\right) \times 100$

$Y_{\mathrm{CH}_{4}}=\mathrm{X}_{\mathrm{CO}_{2}} \times \mathrm{S}_{\mathrm{CH}_{4}}$

A blank on-plasma test was performed in the absence of catalysts at $430^{\circ} \mathrm{C}$. This test yielded almost no $\mathrm{CO}_{2}$ conversion and zero selectivity to $\mathrm{CH}_{4}$.

\section{Results and discussion}

\subsection{Characterization of activated catalysts}

The values of BET surface areas for both the Ni-catalysts (Table 1), obtained from their corresponding $\mathrm{N}_{2}$ adsorption isotherms, are $87,84,85$ and $84 \mathrm{~m}^{2} / \mathrm{g}$ for Ni15PDBD20, Ni15PDBD40, Ni15PDBD60 and Ni15RED470 respectively, which are in agreement with previous studies [9].

The diffraction patterns are shown in Figure 1. For the plasma treated catalysts (Ni15PDBD20, Ni15PDBD40, Ni15PDBD60), the XDR patterns evidence several marked diffraction peaks corresponding to $\mathrm{NiO}$ and $\mathrm{Ni}^{\circ}$ crystalline phases. Whereas on reduced catalyst $\mathrm{Ni15RED} 470$, only the $\mathrm{Ni}^{\circ}$ phase is present. The crystal sizes for $\mathrm{NiO}$ and $\mathrm{Ni}^{\circ}$ calculated from the diffraction patterns using Scherrer equation, using (311) diffractions, are shown in Table 1. At the sight of these XRD analyses it can be already concluded that the hydrogen plasma treatment lead to the formation of $\mathrm{Ni}^{\circ}$ particles similar to the ones obtained by a classical reduction at high temperature. It is however remarkable that the plasma treatment does not lead to a complete reduction of $\mathrm{NiO}$ to $\mathrm{Ni}^{\circ}$.

The basicity of these catalysts was evaluated by means of temperature-programmed desorption of $\mathrm{CO}_{2}\left(\mathrm{TPD}-\mathrm{CO}_{2}\right)$. Basicity may play a role in the methanation reaction since it is required in the adsorption and activation of $\mathrm{CO}_{2}$ [19]. The results of TPD- $\mathrm{CO}_{2}$ are presented 
in Table 1. For all the catalysts, very similar values of $\mathrm{CO}_{2}$ desorption were measured, with very similar desorption profiles. However, it seems that the plasma activation slightly enhances the basicity of the materials since the total amount of $\mathrm{CO}_{2}$ desorbed follows the sequence: Ni15PDBD60 $>$ Ni15PDBD40 $=$ Ni15PDBD20 $>$ Ni15RED470. The $\mathrm{CO}_{2^{-}}$ desorption profiles (not shown) were deconvoluted into 3 contributions at different temperatures: i) $120^{\circ} \mathrm{C}$, ii) $200-250^{\circ} \mathrm{C}$, and iii) $300-350^{\circ} \mathrm{C}$. The desorption peaks with the maximum at approximately $120^{\circ} \mathrm{C}$ and $200-250^{\circ}$ corresponding to the support, can be ascribed to the presence of basic centers of low and/or medium strength (e.g. $\mathrm{OH}$ and $\mathrm{O}$ groups) [20-23]. It has been already proposed that such weak and medium basic sites are necessary to the methanation reaction $[20,24]$. The third peak centered at $300-350^{\circ} \mathrm{C}$ has been ascribed to strong basic sites (e.g. $\mathrm{O}^{2-}$ ) $[22,23]$. Particularly in the case of the plasma treated catalysts, the incorporation of nickel to a ceria-zirconia support leads to the creation of new strong basic sites and to decrease the amount of weak basic ones. In fact, since strong $\mathrm{O}^{2-}$ sites may come from $\mathrm{Ni}$ that has been incorporated to the ceria matrix, this points to a strong interaction between $\mathrm{Ni}$ and ceria from the support that seems to be reinforced as a consequence of the plasma treatment.

\subsection{Hybrid plasma-catalytic methanation: Effect of power supply on catalytic activity}

The $\mathrm{CO}_{2}$ steady-state conversions measured for the conventionally reduced catalyst, $\mathrm{H}_{2}-470^{\circ} \mathrm{C}$ (Ni15RED470), are presented in Fig 2. They increase from $65 \%$ to $80 \%$ with increasing power supply from 4 to $16 \mathrm{~W}$. However, a plateau is already obtained at around 8 $\mathrm{W}$, pointing to an optimal in terms of power supply for this plasma-catalytic process. In all cases, the selectivity to $\mathrm{CH}_{4}$ was found to be higher than $97 \%$.

Fig. 3 shows the $\mathrm{CO}_{2}$ conversion and methane yield measured during $\mathrm{CO}_{2}$ methanation in the presence of a calcined catalyst that was not submitted to any pre-treatment 
(either thermal or plasma). Power supply was varied from 5 to $25 \mathrm{~W}$. The $\mathrm{CO}_{2}$ conversion is very low below $10 \mathrm{~W}$ and reaches $77 \%$ for power supplies higher than $12 \mathrm{~W}$. This fact points to a progressive activation of the catalysts under the plasma conditions used for the catalytic $\mathrm{CO}_{2}$ methanation experiment. This in-situ activation is however not successful at low power supplies, since the activity of the non-pretreated catalyst only equals the one measured for the thermally pretreated Ni15RED470 catalyst, i.e. $80 \% \mathrm{CO}_{2}$ conversion, at power supplies higher than $13 \mathrm{~W}$. The selectivity to $\mathrm{CH}_{4}$ was found to be around $95 \%$ in all experiments, except for the test performed at $23 \mathrm{~W}$, in which a large amount of $\mathrm{CO}$ is observed.

The $\mathrm{CO}_{2}$ conversion and selectivity to methane measured for the hydrogen-plasma pre-treated catalysts at different time-on-stream, i.e. 20,40 and $60 \mathrm{~min}$, are presented respectively in Fig $4 \mathrm{a}$ and $\mathrm{b}$. Already for power supplies between 5 and $6 \mathrm{~W}$ the $\mathrm{CO}_{2}$ conversions reached are in any case very similar to those obtained for the thermally treated Ni15RED470 catalyst, pointing to this plasma treatment as an effective reduction treatment promoting the activity of these Ni-based catalysts in $\mathrm{CO}_{2}$ methanation.

Only in the case of the experiment performed at $4 \mathrm{~W}$, some differences in terms of $\mathrm{CO}_{2}$ conversion can be observed for the plasma pre-treated catalysts at 20, 40 and $60 \mathrm{~min}$. Under these experimental conditions the $\mathrm{CO}_{2}$ conversion is slightly higher for the plasma pre-treated catalysts for $40 \mathrm{~min}$, i.e. Ni15PDBD40 $=73 \%>\mathrm{Ni} 15 \mathrm{RED} 470=63 \%>\mathrm{Ni} 15 \mathrm{PDBD} 60=61 \%$ $>$ Ni15PDBD20 $=35 \%$. This points to an optimal in terms of time-on-stream for this hydrogen-plasma activation pre-treatment, which allows obtaining $\mathrm{CO}_{2}$ conversions even higher than those measured for the conventionally thermal reduced catalyst. The XRD patterns of the plasma pre-treated and the thermally reduced catalysts (Fig.1, Table 1) evidence slightly smaller $\mathrm{Ni}^{\circ}$ crystal sizes for the plasma-treated (around $23 \mathrm{~nm}, 28 \mathrm{~nm}$ for the thermally treated catalysts). The $\mathrm{CO}_{2}$-TPD profiles acquired for the plasma pre-treated catalysts evidence an enhanced presence of strong basic sites for Ni15PDBD60, which can 
explain the lower $\mathrm{CO}_{2}$ conversion measured for this catalyst in comparison to Ni15PDBD40, pointing as well to a stronger interaction between $\mathrm{Ni}$ and the support as the duration of the plasma pre-treatment increases. Let us note here that $\mathrm{H}_{2}$-TPR performed on the Ni15PDBD20 catalysts confirmed the presence of non-reduced $\mathrm{NiO}$ species remaining on the surface of this plasma-treated catalyst, thus explaining its low activity in $\mathrm{CO}_{2}$ methanation and confirming that 20 min treatment is not enough to fully reduce $\mathrm{Ni}$-species.

\section{Conclusion}

Ni-based ceria-zirconia supported catalysts were prepared and pretreated through both a conventional thermal reduction pre-treatment and an ambient temperature hydrogen-plasma pre-treatment. The activity towards $\mathrm{CO}_{2}$ methanation in a hybrid plasma-catalytic adiabatic process was very similar for both thermally and plasma pre-treated catalyst. $\mathrm{CO}_{2}$ conversions as high as $80 \%$ were obtained at low power supplies around 5-6W. This proves that this hydrogen-plasma activation can effectively replace a conventional thermal reduction pretreatment. The Ni-support interaction was strengthened in the catalysts submitted to longer hydrogen-plasma exposure, resulting in slightly higher catalytic activity.

\section{References}

[1] S. Sharma, Z. Hu, P. Zhang, E. W. McFarland, H. Metiu, J. Catal. 278 (2011) 297

[2] G. Centi, S. Perathoner, Stud. Surf. Sci. Catal. 153 (2004) 1

[3] E. Jwa, S. B. Lee, H.W. Lee, Y. S. Mok, Fuel Proc. Technol. 108 (2013) 89

[4] J. Ma, N. N. Sun, X. L. Zhang, N. Zhao, F. K. Mao, W. Wei, Y. H. Sun, Catal. Today 148 (2009) 221 
[5] F. Ocampo, B. Louis, A. C. Roger, Applied Catal. A 369 (2009) 90

[6] Dominik Wierzbicki, Radosław Debek, Monika Motak, Teresa Grzybek, Maria Elena Gálvez, Patrick Da Costa, Catal. Comm. 83 (2016) 5-8

[7] H.K. Song, J.W. Choi, S. H. Yue, H. Lee, B.K. Na, Catal. Today 89 (2004) 27

[8] M. Nizio, R. Benrabbah, M. Krzak, R. Debek, M. Motak, S. Cavadias, M. E. Gálvez, P. Da Costa, Catal.Comm. 83, (2016) 14-17

[9] M. Nizio, A. Albarazi, S. Cavadias, J. Amouroux, M. E. Galvez, P. Da Costa, Int. J. Hyd. Energy, 41 (2016) 11584-11592

[10] Vissokov G.P., Manolovaet K.D., Brakalov L.B.; Journal of Materials Science; 16 (1981) $1716-1719$

[11] W. Xia, O. F. Schlüter, C. Liang, M. W.E Van den Berg, M. Guraya, M. Muhler, Catal. Today 102 (2005) 34-39

[12] L. Rouleau, R. Bacaud, M. Breysse; Applied Catalysis A: General, 104 (1993) 137-147

[13] M. Karches, C. Bayer, P. Rudolf von Rohr, Surf. Coat. Technol. 116-119 (1999) 879-

[14] M.Foix, C. Guyon, M. Tatoulian, P. Da Costa, Catal. Comm., 12 (2010) 20-24

[15] M. Foix, C. Guyon, M. Tatoulian, P. Da Costa, Modern Research in Catalysis, 2, No.3 (2013), DOI: 10.4236/mrc.2013.23011

[16] C.J. Liu, K. Yu , Y-P. Zhang, X. Zhu, F. He , B. Eliasson, Appl. Catal., 47 (2004) 95100

[17] Zhao Y., Pan Y.-X., Cui L., Liu C.-J., Diamond Relat. Mater. 16 (2007) 229-235

[18] R. Bartolomeu, M. Foix, A. Fernandes, M. Tatoulian, M.F. Ribeiro, C. Henriques, Da P. Costa, Catalysis Today, 176 (2011) 234-238

[19] Y. H. Taufiq-Yap, Sudarno, U. Rashid, Z. Zainal, Appl. Catal. A: General 468 (2013) 359 
[20] F. Ocampo, B. Louis, L. Kiwi-Minsker, A. C. Roger, Applied Catalysis A 392 (2011) 3644.,

[21] J. M. García-Vargas, J. L.Valverde, A. de L.-Consuegra, B. Gómez-

Monedero, P.Sánchez, F. Dorado, Appl. Catal. A: General 431-432 (2012) 49

[22] P.V. R. Rao, V. P. Kumar, G. S. Rao, K. V. R. Chary, Catal. Sci. Technol. 2 (2012) 1665

[23] J. Gao, J. Guo, D. Liang, Z. Hou, J.Feia, X. Zheng, Int. J. Hydr. En. 33 (2008) 5493

[24] P.A. Ussa Aldana, F. Ocampo, K. Kobl, B. Louis, F. Thibault-Starzyk, M. Daturi, P.

Bazin, S. Thomas, A.C. Roger, Catalysis Today 215 (2013) 201- 207 


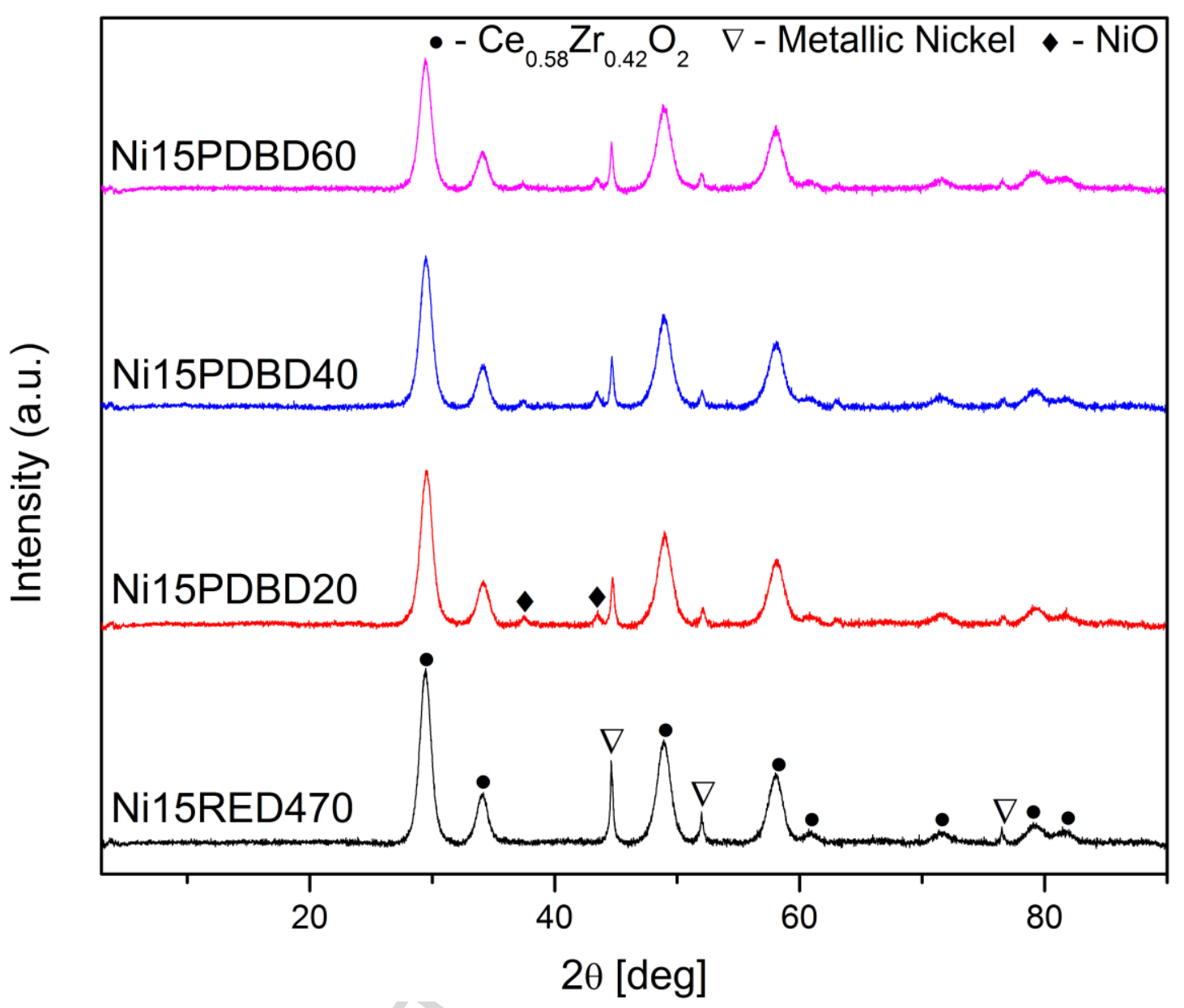

Fig 1. X-Ray Diffractograms of studied catalysts 


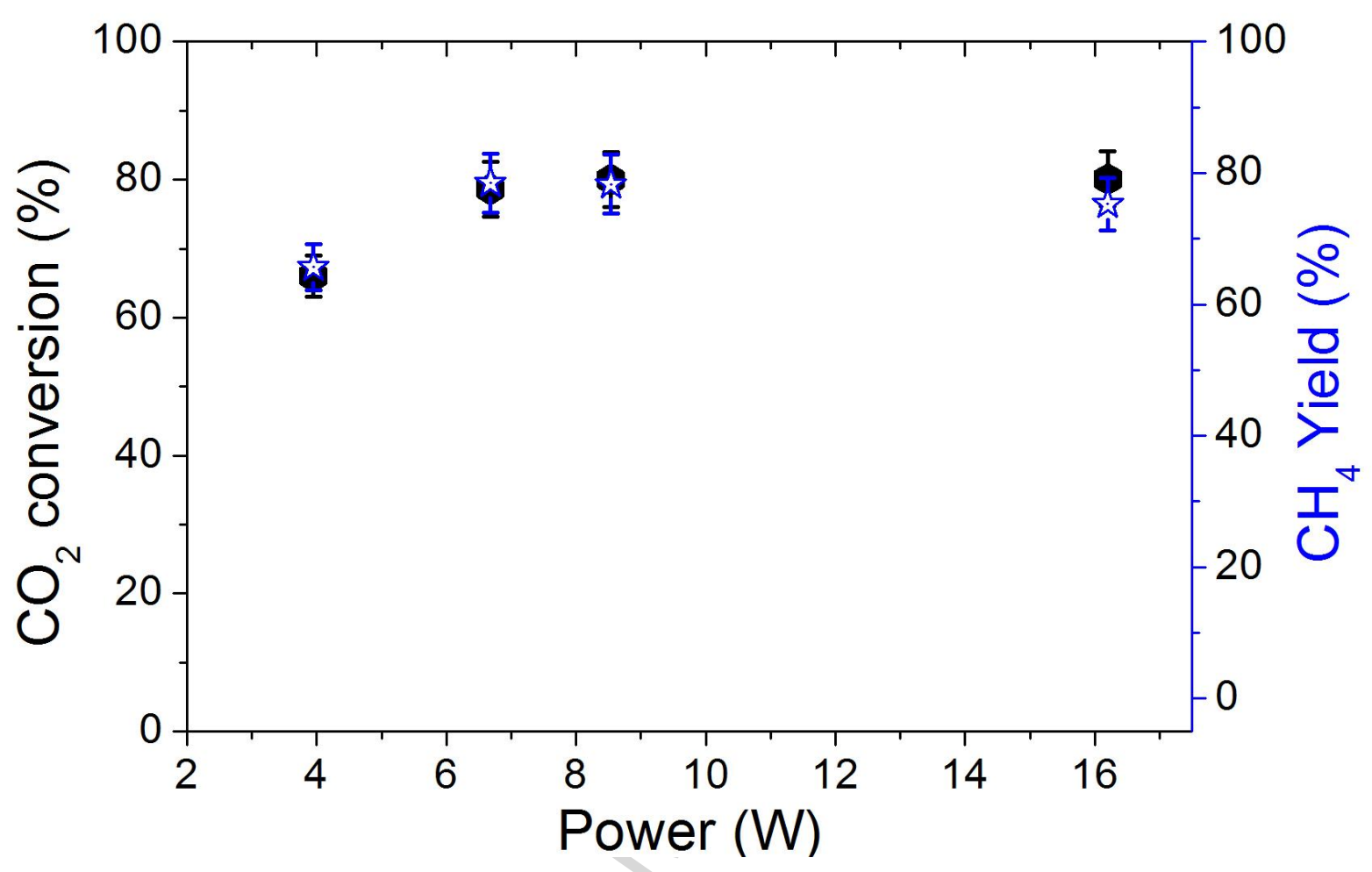

Fig. 2. $\mathrm{CO}_{2}$ conversion and $\mathrm{CH}_{4}$ yield over $\mathrm{Ni} / \mathrm{CeZrO}_{2}$ reduced at $470^{\circ} \mathrm{C}$ in hydrogen 


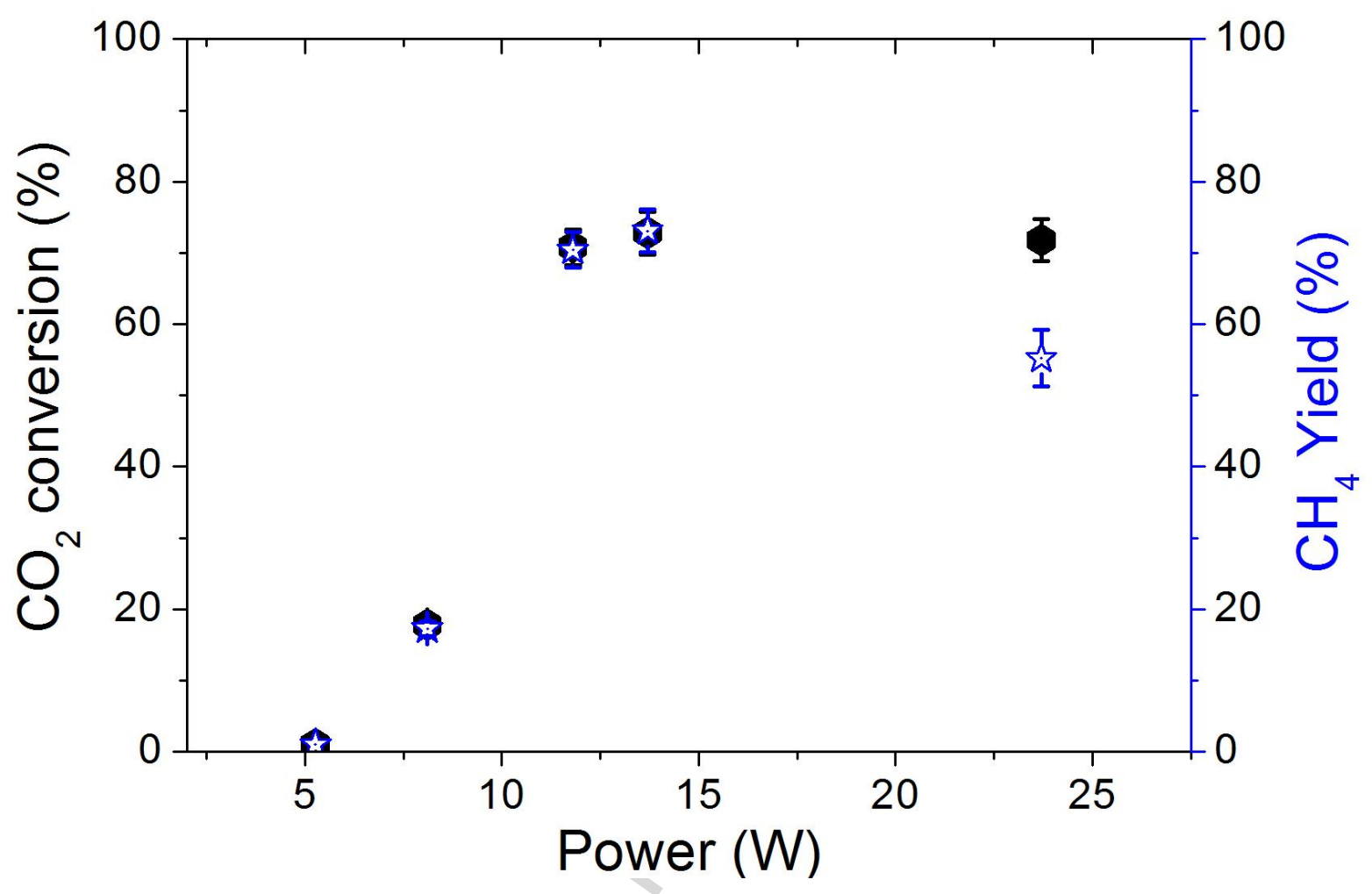

Fig. 3. $\mathrm{CO}_{2}$ conversion and $\mathrm{CH}_{4}$ yield over calcined $\mathrm{Ni} / \mathrm{CeZrO}_{2}$ 

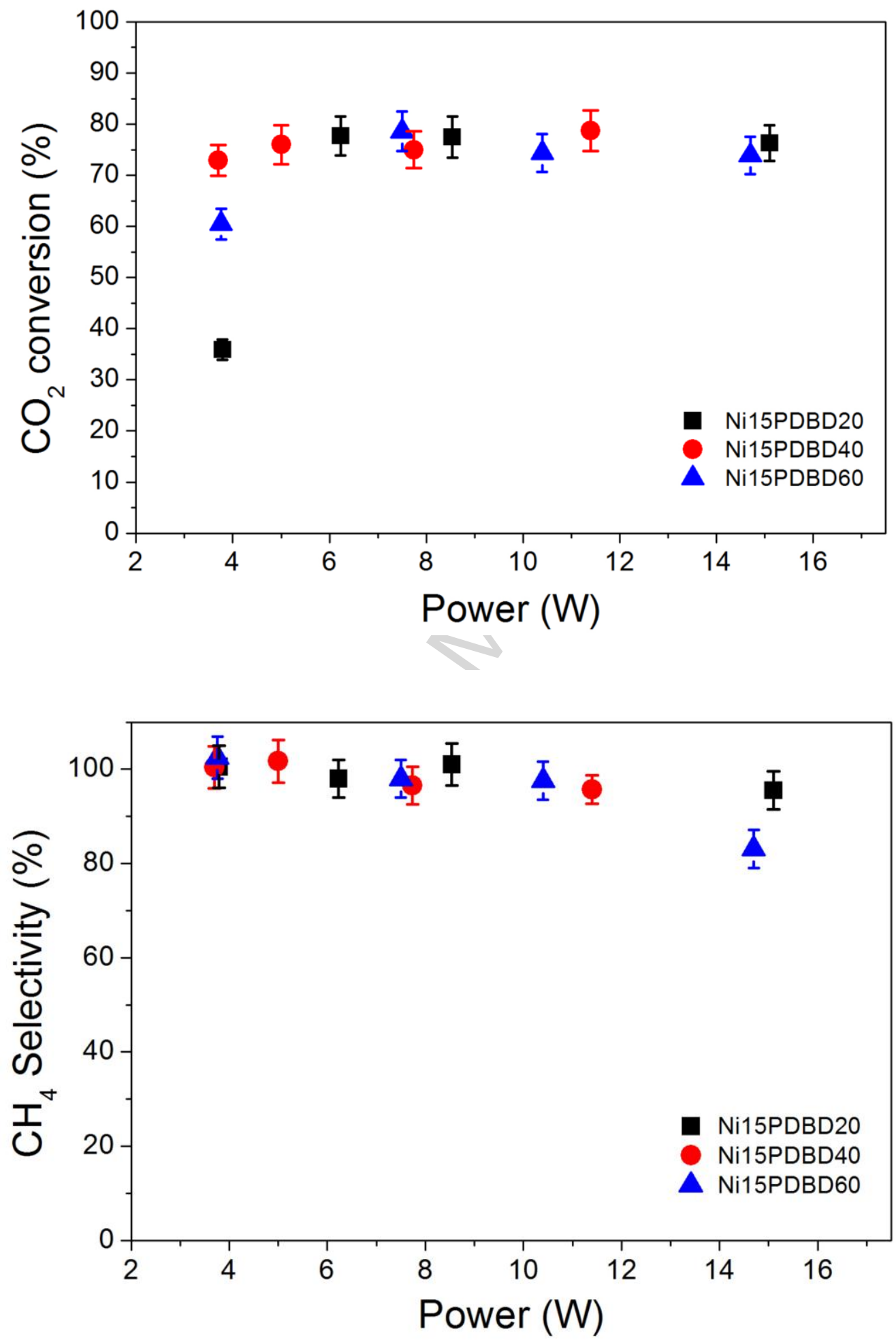

b)

Fig. 4. Activity of $\mathrm{Ni} / \mathrm{CeZrO}_{2}$ pretreated in hydrogen plasma for 20,40 and 60 minutes

a) $\mathrm{CO}_{2}$ conversion, b) $\mathrm{CH}_{4}$ Selectivity 


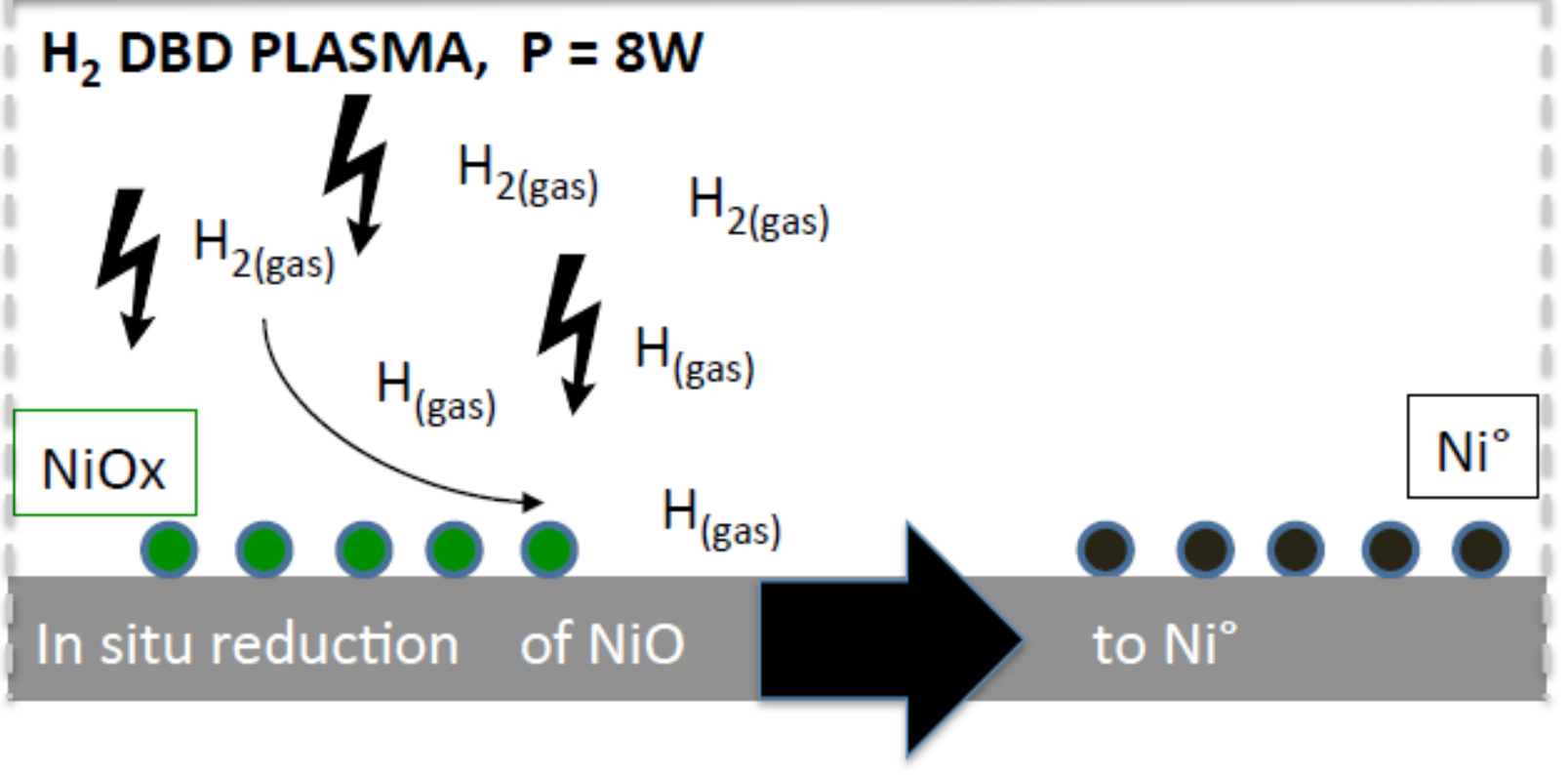

Graphical Abstract 
Table 1. Basicity ( $\mathrm{CO}_{2}$-TPD), Ni-crystal size (XRD), and textural properties for the used catalysts.

\begin{tabular}{|c|c|c|c|c|c|c|c|}
\hline Catalyst & $\begin{array}{c}1 \text { st Peak } \\
\text { basicity } \\
{[\mu \mathbf{m o l} / \mathbf{g}]^{*}}\end{array}$ & $\begin{array}{c}\text { 2nd Peak } \\
\text { basicity } \\
{[\mu \mathbf{m o l} / \mathbf{g}]^{*}}\end{array}$ & $\begin{array}{c}3 \mathrm{rd} \mathrm{Peak} \\
\text { basicity } \\
{[\mu \mathbf{m o l} / \mathbf{g}]^{*}}\end{array}$ & $\begin{array}{c}\text { Total } \\
\text { basicity } \\
{[\mu \mathbf{m o l} / \mathbf{g}]^{*}}\end{array}$ & $\begin{array}{c}\text { NiO } \\
\text { crystallite } \\
\text { size [nm] }\end{array}$ & $\begin{array}{c}\mathbf{N i}^{\circ} \\
\text { crystallite } \\
\text { size [nm] }\end{array}$ & $\begin{array}{c}\mathbf{S}_{\text {BET }} \\
{\left[\mathbf{m}^{2} / \mathbf{g}\right]}\end{array}$ \\
\hline Ni15RED470 & 50 & 100 & 48 & 198 & - & $28.1 \pm 0.3$ & 84 \\
\hline Ni15PDBD20 & 41 & 77 & 94 & 212 & $20.9 \pm 0.3$ & $23.0 \pm 0.3$ & 87 \\
\hline Ni15PDBD40 & 33 & 73 & 108 & 214 & $21.7 \pm 0.3$ & $23.1 \pm 0.3$ & 84 \\
\hline Ni15PDBD60 & 39 & 80 & 112 & 231 & $25.8 \pm 0.3$ & $22.4 \pm 0.3$ & 85 \\
\hline
\end{tabular}

* calculated from $\mathrm{CO}_{2}$ TPD

** calculated from Scherrer formula (XRD patterns) 


\section{Highlights}

- Ni-supported on Ceria-Zirconia for $\mathrm{CO}_{2}$ methanation under DBD plasma

- Hydrogen-plasma pre-treatment proved alternative to thermal reduction

- Plasma pre-treated catalysts show high catalytic activity at low power supply

- Duration of plasma pre-treatment influences Ni-support interaction 